\title{
The Impact of Modern Pharmacy Curriculum on the Student Attitude towards Weight Loss Product Advertisements: A Case Study
}

\author{
Moawia M. Al-Tabakha1", Dana Emad Eddin Obaid', Khairi M. S. Fahelelbom', Bassem Sadek² \\ 'Pharmaceutical Sciences Unit, College of Pharmacy, Al-Ain University of Science and Technology, P.O. Box 64141, Al Ain, UAE. \\ 2Department of Pharmacology and Therapeutics, College of Medicine and Health Sciences, United Arab Emirates University, P.O. Box 17666, Al Ain, UAE.
}

\begin{abstract}
Objective: To investigate whether particular courses in modern pharmacy curriculum equips enrolled students with knowledge/skills to differentiate between different claims of weight loss products. Methods: Claims from weight loss products in UAE market were identified and classified to three categories: indicating safety, indicating effectiveness or indicating convenience. They were assessed in a structured survey for the level of persuasion to undergraduate BSc Pharmacy students $(n=199)$ in the College of Pharmacy (CP) in comparison to other undergraduate students $(n=44)$ from the College of Education (CE) in a University located at Al Ain city, UAE to adopt or recommend the product to their friends. The effect of the particular courses, namely Drug Information and Literature Evaluation (DI) and/or Research Skills (RS), on the level of persuasion was investigated. Results: A trend showing more CP students favoring the different statements was noted particularly if the drug was approved by the FDA $195 \%$ confidence interval (CI) $49.9 \%-63.7 \%$ ) and being a prescription drug $(95 \%$ $\mathrm{Cl} 57.6 \%-71.0 \%)$. Moreover, CP students were more distinctive in favoring the different statements, however students' enrollment in DI and/or RS courses did not demonstrate tangible effect. Conclusion: DI and RS that
\end{abstract}

teach pharmacy students to be conservative in accepting claims failed to yield the expected results. DI course should tackle practical issues such as the one in this study. The integrated didactic courses with experiential components that focus on wellness may also offer an alternative or additional solution. Future similar studies should focus on students exiting the pharmacy program to eliminate some confounding factors.

Key words: Critical Thinking, Drug Information and Literature Evaluation, FDA Approval, Integrated Courses, Obesity, Research Skills.

Correspondence :

Moawia M. Al-Tabakha,

Pharmaceutical Sciences Unit, College of Pharmacy, Al-Ain University of Science and Technology, P.O. Box 64141, Al Ain, UAE.

Tel no: +971 37024872 ; Fax no: +97137024777

E-mail: sphmaa@hotmail.com

DOI: 10.5530/jyp.2016.4.23

\section{INTRODUCTION}

Community pharmacies play a significant role in managing global obesity by providing services such as the supply of weight-loss medication and advice about its use, offering dietary and physical advices and calculating body mass index (BMI), however there is a need for improvement through the development of appropriate undergraduate and postgraduate courses and training programs to equip pharmacists with appropriate knowledge and skills to deliver healthy weight management services. ${ }^{1}$ Extending weight-management services from community pharmacies have been advocated even though weight management clinics in leisure centers and dieticians were preferred over community pharmacies for those trying to lose weight. ${ }^{2}$

Modern pharmacy curriculum is patient oriented, as it emphasizes on evidence-based medicine and integrates science and practice., The College of Pharmacy (CP) in which this study was conducted has obtained was established in 2007 offering BSc pharmacy degree with patient-oriented curriculum. In addition to the national accrediting board in UAE, the college has also obtained the Accreditation Council for Pharmacy Education (ACPE) international certification and is offering a new MSc program in Clinical Pharmacy. Students enrolled in the BSc pharmacy program need to register for the college and University required/elective courses. Of particular interest to the current study were the college required course "i.e. Drug Information and Literature Evaluation (DI)" and the university elective course "Research Skills (RS)" as these two courses enable BSc pharmacy students to retrieve information from different types of resources, evaluate and synthesis evidence-based decisions using critical thinking and problem-solving skills in accordance with the standards 11, 13 and 15 of the ACPE and other recommendations. ${ }^{5,6}$ While drug information and literature evaluation course is pharmacy oriented and therefore applicable to the CP students, research skills course has general applicability and is a University requirement for the two colleges. Graduating pharmacists should be more discriminatory than the CE graduates in terms used and should be able to differentiate between scientific and unrealistic claims of adverts for a variety of medications. Additionally, they should be able to counsel patients on the suitable medications using appropriate resources. ${ }^{7-9}$ This is especially so for the weight loss products as these can be accompanied by adverse effects. ${ }^{10,11}$ Obesity imposes higher risks to many adverse health events including coronary heart diseases, high blood pressure, stroke, type 2 diabetes, metabolic syndrome, cancer, osteoarthritis, sleep apnea and reproductive problems. ${ }^{12-17}$ In countries like UAE, obesity like diabetes, is a serious problem. ${ }^{18}$ For overweight or obese patients, pharmacies are the first place where they seek intervention for their condition, motivated usually by their health. ${ }^{19}$ Community pharmacy intervention in obesity as a risk factor can result in significantly effective and value for money results. ${ }^{20,21}$

Increasing number of obese patients are choosing extreme measures such as elective bariatric surgery or may necessary need to undergo emergency surgery. ${ }^{22,23}$ In addition to following strict diet, exercise and changing life-style, many obese adults use the seemingly easiest approach to include herbal and prescription only medicines to lose weight. ${ }^{24-26}$ In UAE, the only approved pharmacological drug for weight management is the orlistat (Xenical) and many unsolicited weight loss products that find their way to the market get removed by the municipality or the health authorities, as they may contain harmful ingredients. ${ }^{27}$ Cheating through internet and tele-marketing ploys are ways in which harmful, ineffective and sometimes counterfeited drugs find their way to desperate obese patients, who are encouraged by the false claims and/or cheap price. ${ }^{28,29}$ Among popular weight loss products that have not been allowed into the UAE or have been confiscated as a result of unlicensed marketing were Redline, Lipo 6X and Xenadrine RFA-X..$^{30}$ 
We hypothesize that individual courses such as DI and RS that stimulate critical thinking can have influence on the perception of the students toward weight loss product claims. Therefore the purpose of the present study was to assess the impact of BSc pharmacy curriculum and particularly DI course to equip future pharmacists with the tools to differentiate between claims of weight loss products by measuring how persuaded they are by the products' claims using 5-point Likert scale.

\section{METHODS}

The work of this manuscript including the questionnaire were submitted to the University Ethics Committee and received exempt status. The study was carried out in accordance with the Declaration of Helsinki and International Ethical Guidelines.

\section{Weight Loss Product Claims}

The first task was to identify the weight loss products that are not approved by FDA, but available online or in UAE market along with clear package inserts describing the active constituents, indications and claims associated with their use. Only selected claims from orlistat (Xenical) package insert (FDA approved product) and from other researched weight loss products were put together after which they were classified into three categories: indicating the safety of the product, indicating the effectiveness of the product or indicating the convenience of use. Xenical is the only prescription weight loss product approved for UAE market. The search was conducted via different search engines including google (www.google.com) using individual or combination of the phrases: "weight loss product", fat burning product", "slimming product", "miracle weight loss bills" and "anti-obesity product". Pharmacies and department stores were visited to in Al Ain city (UAE) to look for information on general sales weight loss products.

\section{Questionnaire Preparation}

A questionnaire was prepared to include the previously gathered and classified claims. Additional possible confounding factors were included in the questionnaire (although not tested) and included age, height, weight, academic study level and personal interest on weight loss. The enrollment into DI and/or RS course was investigated for the impact on students' attitudes. The level of each claim persuasion was rated in 5-point Likert scale. Additional category "Not Applicable" was added to the end of each scaled item. The student had to assess whether the statement given in a weight loss product can individually persuade him/her to use or recommended the product for a friend.

\section{Study Design}

In this cross-sectional descriptive study, the questionnaire was pilot tested and modified to be more explicit to the respondents. It was then introduced to the CP students from different study levels. The BSc Pharmacy program in the CP consists of 9 study Semesters distributed over 4.5 years of study. Additionally, the questionnaire was distributed to the College of Education (CE) to act as control in order to test the impact of the pharmacy curriculum, especially the DI course. Students currently enrolled in either courses are at a course completion stage since the questionnaire was distributed at the end of the Semester. The results from the 5 -point score were further summarized by calculating the proportion of students reporting a persuasion level of 4 or 5 as in favor of a product's claim.

\section{Statistical Analysis}

Descriptive and analytic statistics were performed using SPSS, version 21 (SPSS Inc, Chicago, IL). The preparations of the graph figures were conducted using Microsoft Excel (Microsoft Office 2010, Redmond, WA).

\section{RESULTS}

\section{Weight Loss Product Claims}

Searching the internet and UAE market resulted in the following weight loss products being identified having complete description (but were not FDA approved): Dr.Tim's Raspberry Ketone (Dr. Tim's, USA); Dr. Tim's Garcinia Cambogia Extract (50\% hydroxycitric acid (HCA), from Dr. Tim's, USA); Kordel's Citrimax Plus (Kordel, New Zealand); XL-S Medical Fat Binder (Omega Pharma, Belgium); Chitosan (NOW, USA); Capsiplex (Advanced Health, UK); Holland \& Barrett Super Green Tea Diet (Holland \& Barrett Retail Limited, UK); Phase 2 (NOW, USA). Products from different companies were included in the study even if they contained identical active ingredients, since the purpose of the study was to measure the claims of these products rather than the products themselves. Information from these products and from Xenical are presented in Table 1.

\section{Participants}

A total of 199 students enrolled in the BSc pharmacy program and 48 students from the CE participated in answering the distributed questionnaire. According to the information from the University registration office, about $67 \%$ of pharmacy students have participated in this survey while $17 \%$ have responded from the CE. The percentage of pharmacy participants who completed the RS course was $34.4 \%$, while this accounted for $37.5 \%$ in the CE. The majority of pharmacy students answering information about their weight and height (67.2\%) had a normal or healthy weight according to the BMI classification by the US CDC (i.e. 18.5 to 24.9 ). In contrast, $56.4 \%$ of participating students from the CE had normal weight.

\section{Survey Results \\ Evaluation of Product's Safety Statements}

The item specifying that the drug is FDA approved received highest favor in both colleges. With the CP students, the proportion of students persuaded by this statement was $56.8 \%$ of the participants (95\% CI $49.9 \%$ to $63.7 \%$ ) and $47.9 \%$ (95\% CI $33.4 \%$ to $62.4 \%$ ) in the CE. The least convincing statement for the $\mathrm{CP}$ and $\mathrm{CE}$ was that the product's drug is safe since it works in the stomach and digestive tract (Figure 1). The 95\% CIs were $23.3 \%$ to $36.0 \%$ and $4.3 \%$ to $24.8 \%$ for the CP and CE respectively, indicating no significant difference.

Generally, CP students voted more positively to the different items tested. The impact of using different claims was more pronounced than the effect of participant type within each college. For example, percent of all possible significant difference detected (as evident from 95\% CI results) was $33.3 \%$ in the CP participants compared to $13.3 \%$ in the CE when considering the type of claim in each subgroup. In contrast, the variability in favoring different claims because of participant type (i.e. college, enrolled or not enrolled in a course) was in the range from $0.0-10.7 \%$ of all possible differences (Table 2).

Students from the CP and currently enrolled/completed DI and RS favored the statement of FDA approval of the drug (95\% CI 55.6\% $83.9 \%$ ) more than the student from the CE (95\% CI 13.4\%-53.2\%). No other differences were detected because of participant type within or between the colleges.

\section{Evaluation of Product's Efficacy Statements}

The results show that for the drug to be dispensed by a prescription was the highest persuading statement among the participants of the CP (95\% CI $57.6 \%-71.0 \%)$ and the CE (95\% CI $33.4-62.4 \%$ ), (Figure 2). On the other hand, statement indicating that non-clinical studies showed the drug to bind to fat and cholesterol in the digestive system received the 
Al-Tabakha et al.: Modern Pharmacy Curriculum
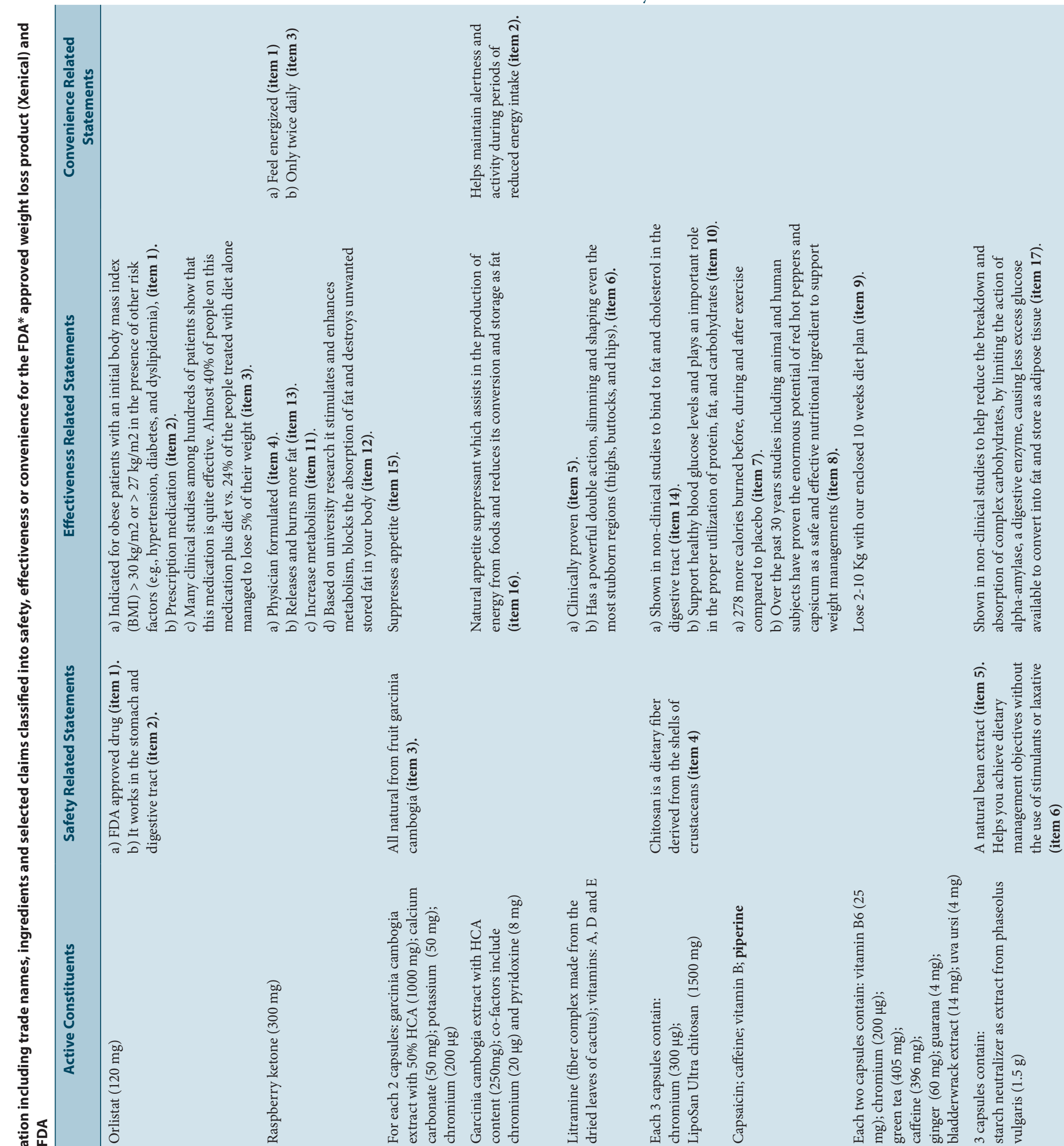

है
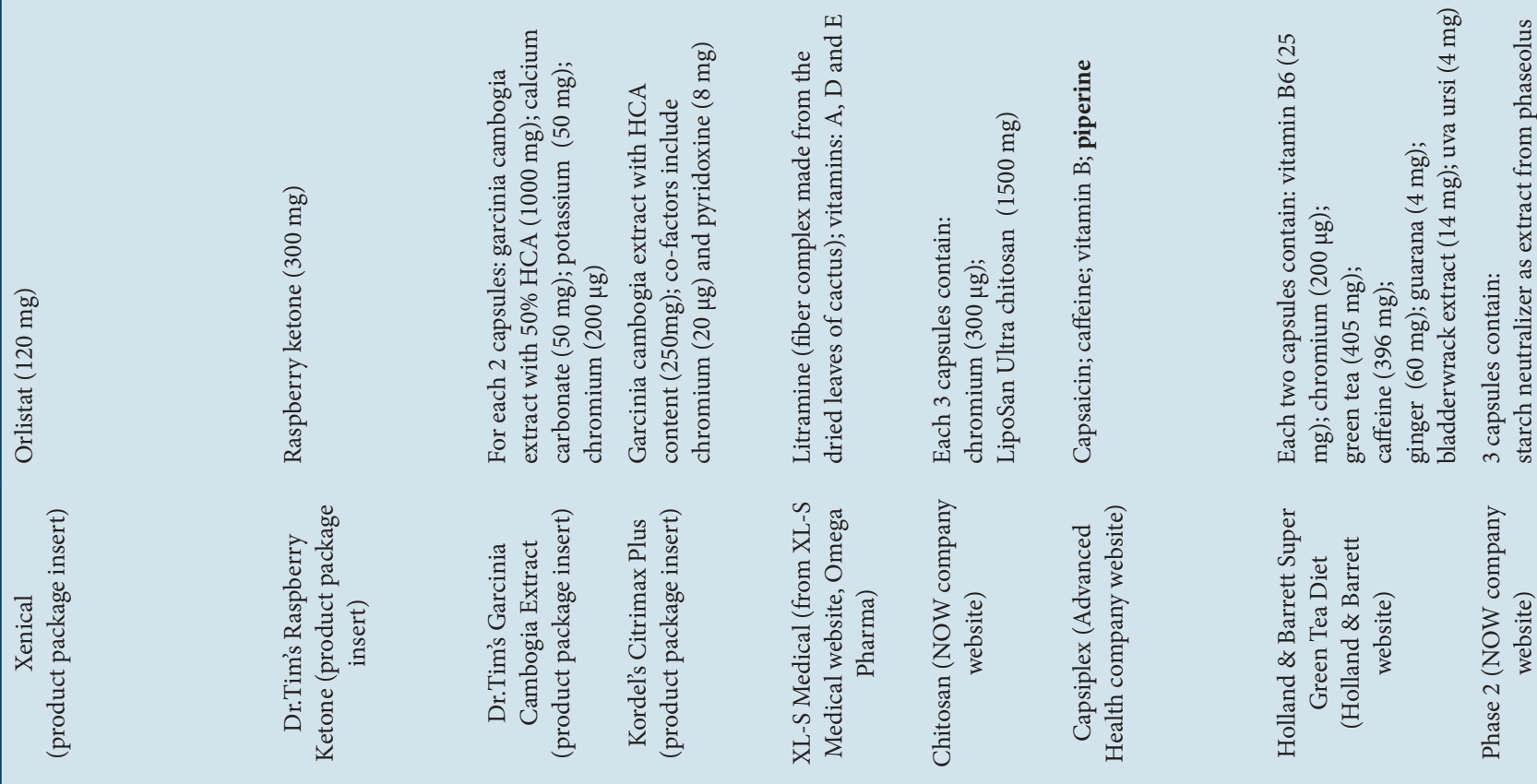


\begin{tabular}{|c|c|c|}
\hline $\begin{array}{l}\text { Statements on } \\
\text { Product's Safety }\end{array}$ & $\begin{array}{l}\text { Number of Differences } \\
\text { By Participant Type }\end{array}$ & $\begin{array}{l}\text { \% from All Possible } \\
\text { Differences }\end{array}$ \\
\hline Item 1 & 1 & $3.6 \%$ \\
\hline Item 2 & 3 & $10.7 \%$ \\
\hline Item 3 & 0 & $0.0 \%$ \\
\hline Item 4 & 0 & $0.0 \%$ \\
\hline Item 5 & 0 & $0.0 \%$ \\
\hline Item 6 & 0 & $0.0 \%$ \\
\hline
\end{tabular}

Table 3: Number and percent of differences detected based on different participant type for favoring each drug effectiveness statement (refer to table I for item description) based on $\mathbf{9 5 \%}$ confidence interval results

\begin{tabular}{ccc}
\hline $\begin{array}{c}\text { Statements on Product's } \\
\text { Effectiveness }\end{array}$ & $\begin{array}{c}\text { Number of Differences } \\
\text { By Participant Type }\end{array}$ & $\begin{array}{c}\text { \% from All } \\
\text { Possible } \\
\text { Differences }\end{array}$ \\
\hline Item 1 & 0 & $0.0 \%$ \\
Item 2 & 0 & $0.0 \%$ \\
Item 3 & 0 & $0.0 \%$ \\
Item 4 & 1 & $3.6 \%$ \\
Item 5 & 1 & $3.6 \%$ \\
Item 6 & 0 & $0.0 \%$ \\
Item 7 & 0 & $0.0 \%$ \\
Item 8 & 0 & $0.0 \%$ \\
Item 9 & 1 & $3.6 \%$ \\
Item 10 & 4 & $14.3 \%$ \\
Item 11 & 0 & $0.0 \%$ \\
Item 12 & 0 & $0.0 \%$ \\
Item 13 & 0 & $0.0 \%$ \\
Item 14 & 1 & $3.6 \%$ \\
Item 15 & 0 & $0.0 \%$ \\
Item 16 & $0.0 \%$ \\
Item 17 & $0.0 \%$ \\
\hline
\end{tabular}

lowest persuading statement regarding the drug's effectiveness in the $\mathrm{CP}$ (95\% CI $24.2 \%$ - 37.1\%) and the CE (95\% CI 12.4\% - 37.6\%).

In contrast to the results of safety statements, only pharmacy students were able to provide discriminatory favoring responses to different question unlike the CE students. So, CP participants gave different responses to different statements. Of possible detectable differences according to the $95 \%$ CI results, $19.1 \%$ differences in favoring the rated items were identified. In addition, participants from the CP including those who neither had the course RS nor DI favored item 10: "supports healthy blood glucose levels and plays an important role in the proper utilization of proteins, fats and carbohydrates" more than the corresponding groups from the CE. No other clear indicators could be based on the participant type influencing the results.

\section{Evaluation of Product's Convenience Statements}

In this study, only 3 items were evaluated regarding the convenience of using the weight loss products (Figure 3 ). The differences were only observed within the CP. For example, only $15.2 \%$ (95\% CI $2.4 \%-27.9 \%)$ favored the statement about the convenience of the energizing effect in the group who completed or currently enrolled in DI but not RS compared to the much higher persuasion rates in all CP participants (95\% CI 31.4\% - 45.0\%). Similar trends were observed in the group never enrolled in DI or RS (95\% CI 33.1\% - 54.2\%) and in the group completed or currently enrolled in the RS (95\% CI 38.7\% -72.4\%). Also, the group who completed or currently enrolled in DI and RS had lower persuasion rate $(95 \%$ CI $10.3 \%$ - 36.3\%) compared to the group who never had the two courses in the CP $(95 \%$ CI $41.1 \%-62.4 \%)$.

\section{DISCUSSION}

Nine products related to weight loss were included in this study and some claims regarding their safety, efficacy and convenience of use were determined. Some of these claims could have belonged to combination of categories, but for organizing purposes, they were listed in one category. For example, the statement "FDA approved" indicates both effectiveness and safety, but in our survey we listed the statement under the safety statement of the product, not the effectiveness.

The CP group had a higher percentage of students younger than 20 years compared to the CE. This also applies for the average age in both groups $(\mathrm{p}=0.001)$. However, this difference in age was small (19.6 vs 23.7 years) and was not correlated with significant imbalance in the distribution of students over the different academic levels. The BMI results did not show any significant difference between the $\mathrm{CP}$ and the $\mathrm{CE}$ and the majority of students $(>50 \%)$ reported normal body weight. No male students were involved in the CE participants unlike the CP that involved $22.2 \%$ male students. The impact of this towards the discrimination between different statements associated with the weight loss products is unclear, but it is expected from a pharmacy program to provide students with abilities to be more vigilant of health terms related to obesity compared to $\mathrm{CE}$ students. ${ }^{31}$ While RS course is a University elective that can be taken at any academic level, DI course is a college required course that is taken at the beginning of the third year of the pharmacy program. The survey was conducted at the end of the academic semester when any student that was enrolled in the DI or RS course can be considered as have completed the course. Therefore, students who were enrolled in DI or RS at the time of the survey distribution were considered with the students who completed the course.

Generally, pharmacy students consistently reported higher percentages of persuasion by the statements of weight loss products. This may be partially explained by the terms used which are more recognizable by the $\mathrm{CP}$ compared to $\mathrm{CE}$ students and the presence of male participants from the CP. The use of the term "FDA approval" resulted in a significant persuasion rate compared to other safety statements used for the $\mathrm{CP}$ participant. Also, the persuasion rate by $\mathrm{CP}$ students completing both RS and DI courses was significantly higher compared CE students who did not complete the RS course. Although the highest rate of persuasion was for the FDA approval in the CE, it was only significantly different from items 2 and 4 of safety statements. Additionally, students from CE who completed/currently enrolled in RS rated the FDA approval as more convincing compared to items 2, 3 and 4 .

Similar trends were observed with statements associated with the products' efficacy. A "prescription drug" received was significantly highest persuading efficacy statement reported by the CP students, except for the product being physician formulated. The number of persuasion differences by question type was reduced when considering the enrollment 


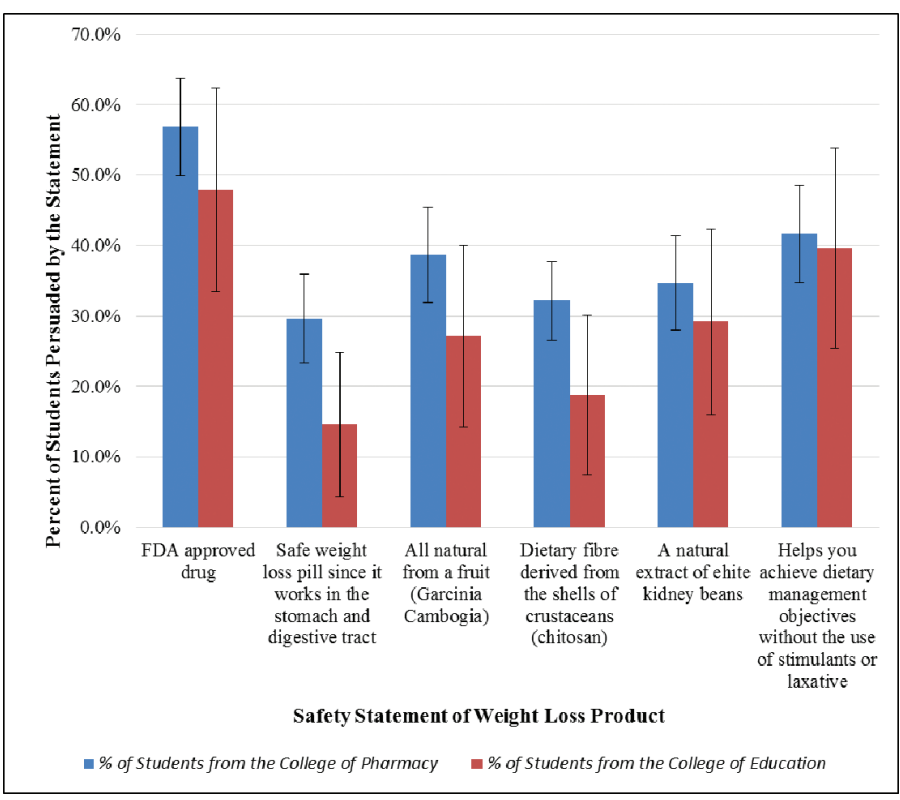

Figure 1: Percentage with $95 \% \mathrm{Cl}^{1}$ of participating students from the $\mathrm{CP}^{2}$ and $\mathrm{CE}^{3}$ who are persuaded by the safety statement of the weight loss products.

${ }^{1}$ : Confidence Interval.

2: College of Pharmacy.

3: College of Education.

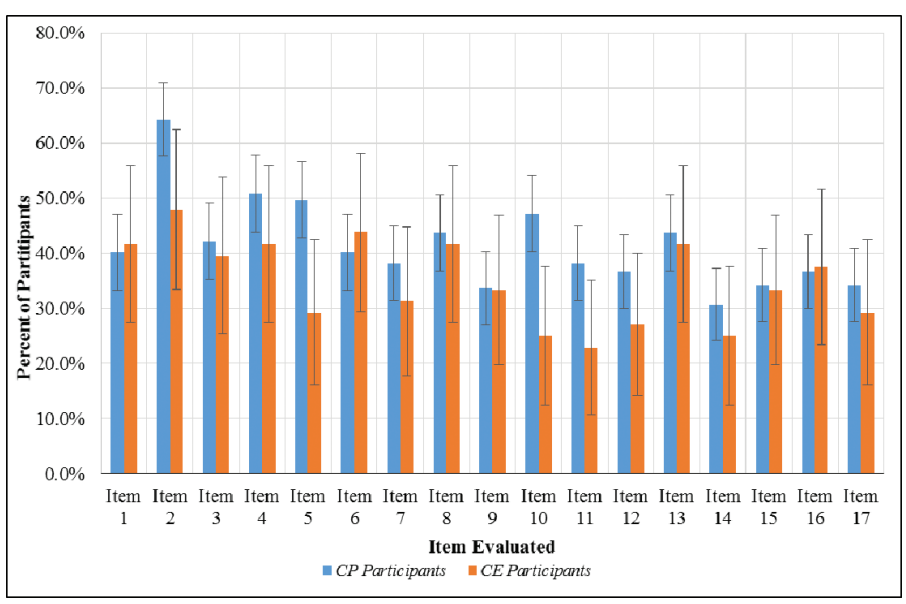

Figure 2: Percentage with $95 \% \mathrm{Cl}^{1}$ of participants in favor of the weight loss product effectiveness statements (refer to table I for item description) from the $C P^{2}$ and $C E^{3}$.

${ }^{1}$ : Confidence Interval.

2: College of Pharmacy.

3: College of Education.

in RS and/or DI courses. The CE participants also recorded the highest rate in the same item recorded by CP participants, but was not significantly different from the persuasion by other statements. For a drug to be dispensed by a prescription indicates that physician and pharmacist are involved. This probably explains the confidence of the participants that the product would be effective for reducing body weight. The statement that the product is clinically proven meant more to the CP students than $\mathrm{CE}$. This indicates the awareness of the $\mathrm{CP}$ participants that clinical trials are the pillar of evidence-based medicine as compared to the CE.

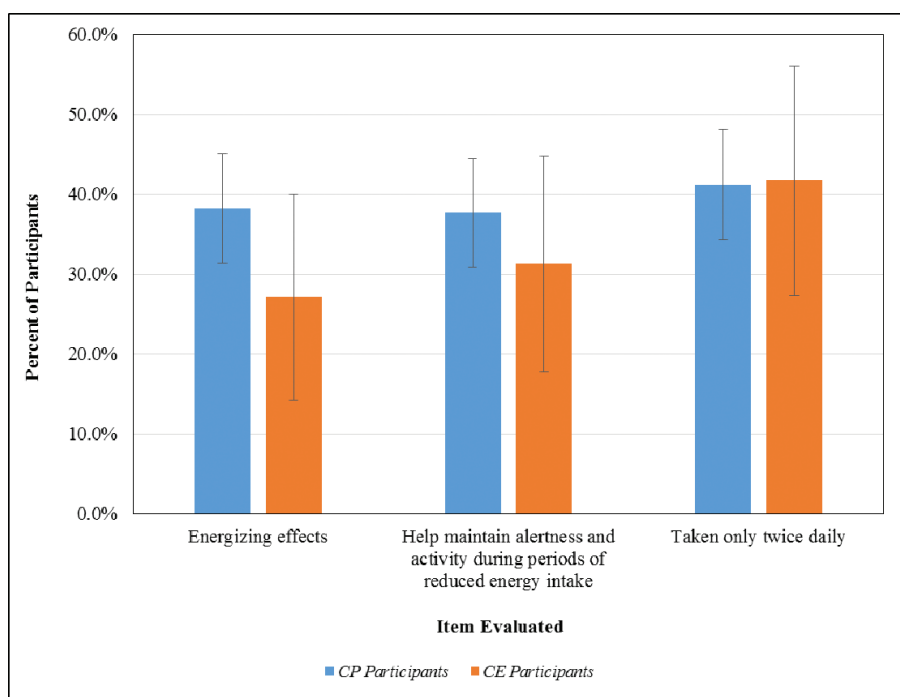

Figure 3: Percentage with $95 \% \mathrm{Cl}^{1}$ of participants in favor of the weight loss product's convenience statements from the $\mathrm{CP}^{2}$ and $\mathrm{CE}^{3}$.

${ }^{1}$ : Confidence Interval.

${ }^{2}$ : College of Pharmacy.

3 : College of Education.

Different types of participants from the CP were convinced differently by the convenience statement that the product is having energizing effect. The lowest recorded persuasion by the statement was for the participants who currently enrolled or who have completed the course DI (but not RS), (15.2\%). The latter finding may indicate that this subgroup of students believes that the statement sounded advertising than real scientific. However, no such effect was observed for students completing both RS and DI. Also, the CE participants did not indicate differences in persuasion regardless of the question type or participant type.

Students did not have the opportunity to check the validity of the statements or the scientific evidence behind them. Consequently, they had to rely on their personal attitudes from the knowledge and practice they had. Accordingly, DI course should provide more news publication and compare them to the original research for the students to become familiar with the types of baseless or nonscientific statements and reinforce course goals. ${ }^{32,33}$ Also offering integrated courses may enhance pharmacy student ability to be competent in providing health related services. Previous researches demonstrated that integrated pharmacy curricula especially between didactic and experiential components can help students develop their own integrations. ${ }^{3,34-37}$ In the future, similar studies should focus on students exiting the program to better assess performance of the program rather than individual courses. Also, this will enable the elimination of some confounding factors associated with the study and better assess the need for integrated courses.

The current study did not compare students from different age groups or from different academic levels as it was focused on the significant effect of special courses. CP students from senior levels tend to be more familiar with weight loss products and the mechanism by which they act as they progress through academic years compared to junior students. Moreover, new drugs are being approved by the FDA, e,g. lorcaserin and phentermine/topiramate extended release in 2012 and naltrexone/ bupropion in 2014, and the information may not be readily available to the current students. ${ }^{38}$ Consequently, continuing education on the newly approved and licensed products needs to be available to the graduating students. 


\section{CONCLUSION}

Most chronic diseases are caused by unhealthy lifestyle. Therefore, current pharmacy curriculum need to focus on the area of wellness rather than mainly on drugs and diseases. The current study failed to demonstrates that DI and/or RS courses are capable of imparting a different attitudes towards the claims of weight loss products. This necessitates changing the relevant course design to focus on practical issues such as the one in this study. Alternatively, courses can so that didactic courses to include experiential component. This study was not designed for the students to assess the claims themselves, since the settings of the administered questionnaire did not allow the student to check the validity of the claims.
Similar future studies should focus on the students exiting the pharmacy program to better evaluate both the knowledge and skills gained throughout the program.

\section{ACKNOWLEDGEMENT}

We are deeply grateful for cooperation received from the College of Pharmacy and the College of Education Staff and Students for the time they spent to allow for the questionnaire to be distributed and completed.

\section{CONFLICT OF INTEREST}

The authors have no conflict of interests to declare.

\section{ABBREVIATIONS USED}

CP: College of Pharmacy; CE: College of Education; DI: Drug Information and Literature Evaluation; RS: Research Skills; ACPE: Accreditation Council for Pharmacy Education; BMI: Body Mass Index; FDA: The US Food and Drug Administration; Cl: Confidence Interval; UAE: United Arab Emirates.

\section{ABOUT AUTHOR}

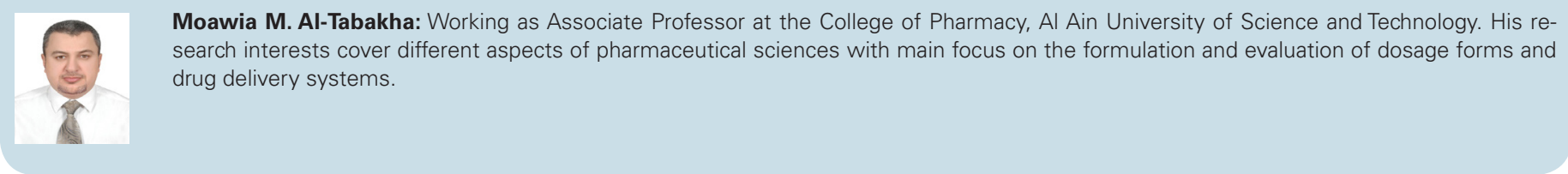

\section{REFERENCES}

1. Newlands RS, Watson MC, Lee AJ. The provision of current and future Healthy Weight Management (HWM) services from community pharmacies: a survey of community pharmacists' attitudes, practice and future possibilities. Int $J$ Pharm Pract. 2011;19(2):106-14

2. Krska J, Lovelady C, Connolly D, Parmar S, Davies MJ. Community pharmacy contribution to weight management: identifying opportunities. Int J Pharm Pract. 2010;18(1):7-12

3. Husband AK, Todd A, Fulton J. Integrating science and practice in pharmacy curricula. Am J Pharm Educ. 2014;78(3):63.

4. El-Awady el SE, Moss S, Mottram D, O'Donnell J. Student perspectives on pharmacy curriculum and instruction in Egyptian schools. Am J Pharm Educ. 2006;70(1):9.

5. ACPE. Accreditation standards and guidelines for the professional program in pharmacy leading to the doctor of pharmacy degree Chicago, illinois ACPE; 2011

6. Katajavuori N, Hakkarainen K, Kuosa T, Airaksinen M, Hirvonen J, Holm Y. Curriculum reform in Finnish pharmacy education. Am J Pharm Educ. 2009;73(8):151.

7. Al-Tabakha MM, Akoulah LH, Fahelelbom KM. Drug Information in Community Pharmacy and Outpatient Pharmacy in Al Ain City, U.A.E.: A Descriptive Study. Int J Pharm. 2013;3(2):316-22

8. Owusu-Obeng A, Weitzel KW, Hatton RC, et al. Emerging roles for pharmacists in clinical implementation of pharmacogenomics. Pharmacotherapy. 2014;34(10):1102-12

9. Gershman JA, Fass AD. Medication safety and pharmacovigilance resources for the ambulatory care setting: enhancing patient safety. Hosp Pharm. 2014;49(4):363-8.

10. Khorassani FE, Misher A Garris S. Past and present of antiobesity agents: Focus on monoamine modulators. Am J Health Syst Pharm. 2015;72(9):697-706.

11. Hainer V. Overview of new antiobesity drugs. Expert Opin Pharmacother 2014;15(14):1975-78

12. Ogden $\mathrm{CL}$, Carroll MD, Kit BK, Flegal KM. Prevalence of obesity in the United States, 2009-2010. NCHS Data Brief. 2012:1-8.

13. Rochlani Y, Pothineni NV, Mehta JL. Metabolic Syndrome: Does it Differ Between Women and Men? Cardiovasc Drugs Ther. 2015;29(4):329-38.

14. Sahoo K, Sahoo B, Choudhury AK, Sofi NY, Kumar R, Bhadoria AS. Childhood obesity: causes and consequences. J Family Med Prim Care. 2015;4(2):187-92

15. Katib A. Mechanisms linking obesity to male infertility. Cent European J Urol. 2015:68(1):79-85

16. Kyrou I, Randeva HS, Weickert MO. Clinical Problems Caused by Obesity. In: De Groot LJ, Beck-Peccoz P, Chrousos G, et al., eds. Endotext. South Dartmouth (MA): MDText.com, Inc.; 2000.
17. Van Gaal L, Scheen A. Weight Management in Type 2 Diabetes: Current and Emerging Approaches to Treatment. Diabetes Care. 2015;38(6):1161-72.

18. Al-Tabakha MM, Arida Al. Recent challenges in insulin delivery systems: a review. Indian J Pharm Sci. 2008;70(3):278-86

19. Dobrucka K, Maly J, Vlcek J. [Analysis of pharmaceutical care in dispensing of over-the-counter orlistat]. Ceska Slov Farm. 2012;61(6):276-81.

20. Todd A, Moore $\mathrm{HJ}$, Husband AK, et al. Community pharmacy interventions for public health priorities: protocol for a systematic review of community pharmacy-delivered smoking, alcohol and weight management interventions. Syst Rev. 2014;3(1):93.

21. Malone M, Alger-Mayer SA. Pharmacist intervention enhances adherence to orlistat therapy. Ann Pharmacother. 2003;37(11):1598-602.

22. Mullins MM. Blood Pressure and the Obese. Nurs Clin North Am. 2015;50 (2):241-55

23. Memarian E, Sundquist K, Calling S, Sundquist J, Li X. Country of origin and bariatric surgery in Sweden during 2001-2010. Surg Obes Relat Dis 2015;11(6):1332-41.

24. Barja-Fernandez S, Leis R, Casanueva FF, Seoane LM. Drug development strategies for the treatment of obesity: how to ensure efficacy, safety, and sustainable weight loss. Drug Des Devel Ther. 2014;8:2391-400.

25. Del Re AC, Frayne SM, Harris AH. Antiobesity medication use across the veterans health administration: patient-level predictors of receipt. Obesity (Silver Spring) 2014;22(9):1968-72

26. Manning S, Pucci A, Finer N. Pharmacotherapy for obesity: novel agents and paradigms. Ther Adv Chronic Dis. 2014;5(3):135-48.

27. Reporter. 5 weightloss medicines removed from shelves in UAE. UAE: khalee Times; 2014.

28. Liang BA, Mackey TK, Archer-Hayes AN, Shinn LM. Illicit online marketing of lorcaserin before DEA scheduling. Obesity (Silver Spring). 2013;21(5):861-4.

29. Mackey TK, Liang BA. Pharmaceutical digital marketing and governance: illicit actors and challenges to global patient safety and public health. Global Health 2013;9(1):45.

30. Samihah Zaman. Ten weight-loss products banned. Gulf News. Abu Dhabi: Gulf News; 2011

31. Ghia C, Jha R, Rambhad G. Assessment of the impact of pharmaceutical advertisements on patient's drug consuming behaviour: A questionnaire based survey. J Young Pharm. 2014;6(2):58-63.

32. Motl SE, Timpe EM, Eichner SF. Evaluating the accuracy of health news publications in a drug literature evaluation course. Am J Pharm Educ. 2006:70(4):83.

33. Harpe SE, Phipps LB. Evaluating student perceptions of a learner-centered drug 
literature evaluation course. Am J Pharm Educ. 2008;72(6):135.

34. Pearson ML, Hubball HT. Curricular integration in pharmacy education. Am J Pharm Educ. 2012;76(10):204.

35. Sookaneknun P, Suttajit S, Ploylearmsang C, Kanjanasilp J, Maleewong U Health promotion integrated into a Thai PharmD curriculum to improve pharmacy practice skills. Am J Pharm Educ. 2009;73(5):78.

36. Karimi R, Arendt CS, Cawley P, Buhler AV, Elbarbry F, Roberts SC. Learning bridge: curricular integration of didactic and experiential education. Am J Pharm Educ. 2010;74(3):48

37. Terri M. Wensel AEB, Michael G. Kendrach. Design, implementation, and assessment of an Integrated Pharmacy Applications course series. Currents in Pharmacy Teaching and Learning. 2014;6(5):706-15.

38. Kakkar AK, Dahiya N. Drug treatment of obesity: current status and future prospects. Eur J Intern Med. 2015;26(2):89-94 